\title{
Effects of Tyre Pressure on Vehicle Suspension Performance
}

\author{
M. Hamed, B. Tesfa, F. Gu, A.D.Ball \\ Centre for Efficiency and Performance Engineering University of Huddersfield, Huddersfield, UK \\ E-mail address: U0951001@hud.ac.uk, b.c.tesfa@hud.ac.uk
}

Keywords: Suspension performance; Full Vehicle Models; Condition monitoring; vehicle tyre inflation;

\begin{abstract}
Incorrect inflation pressures in tyres affects the vehicle handling, passenger comfort and braking conditions in addition to causing a reduction in fuel efficiency and tyre life. To address this problem, mathematical models have been produced and an experimental validation has been carried out. The models were developed with 7-DOF, for a full car system, using MATLAB programs. In the simulation study, the suspension faults have been considered by running the models with a range of inflation pressures at four conditions i.e. at standard pressure (2.3bar) and 1.5bar on the passenger wheel, driver wheel and front wheels. In each case, an analysis was carried out on the performances of the suspension in terms of ride comfort, road handling and stability of the vehicle followed by the presentation of the results obtained. In addition, the influence of parameter variations on transfer functions as a fault detection of suspension has been introduced. This approach has been used when detecting faults of vehicle tyres being under-inflated $35 \%$ and also to detect other suspension faults in the future.
\end{abstract}

\section{INTRODUCTION}

The suspension is linked with tyres which provide traction between the vehicle and the road while providing a flexible cushion that absorbs shock. Tyres are the most important parts of a car. They have to transmit all drive, brake and steering forces to the road through a very small contact patch. In addition, provide friction to allow the vehicle performs its normal operations.

The selection of a correct inflation pressure is critical to the successful operation of the tyre. It is well-known that operation of a tyre at higher inflation pressure than the required pressure may cause uneven tread wear, degrade vehicle ride and comfort, and increase susceptibility to impact damage. Similarly, operating the tyre at lower than required pressure may also cause uneven tread wear, but can potentially lead to fatigue breakdown of the tyre"s internal structure resulting in tread separation or other structural failure and also degrade the car performance by increasing vibrations [1]. In addition, under-inflated tyres are associated with environment costs such as increased greenhouse gases, higher fuel consumption and tyre lifetime decreases with 20 percent for every 0.2 bar under-inflation [2]. The tyre pressure is not supervised regularly by the drivers. It is estimated nearly 50 percent of all cars drive with reduced tyre pressure [3]. 


\section{Tyre Industry Council survey of (1072) tyres}

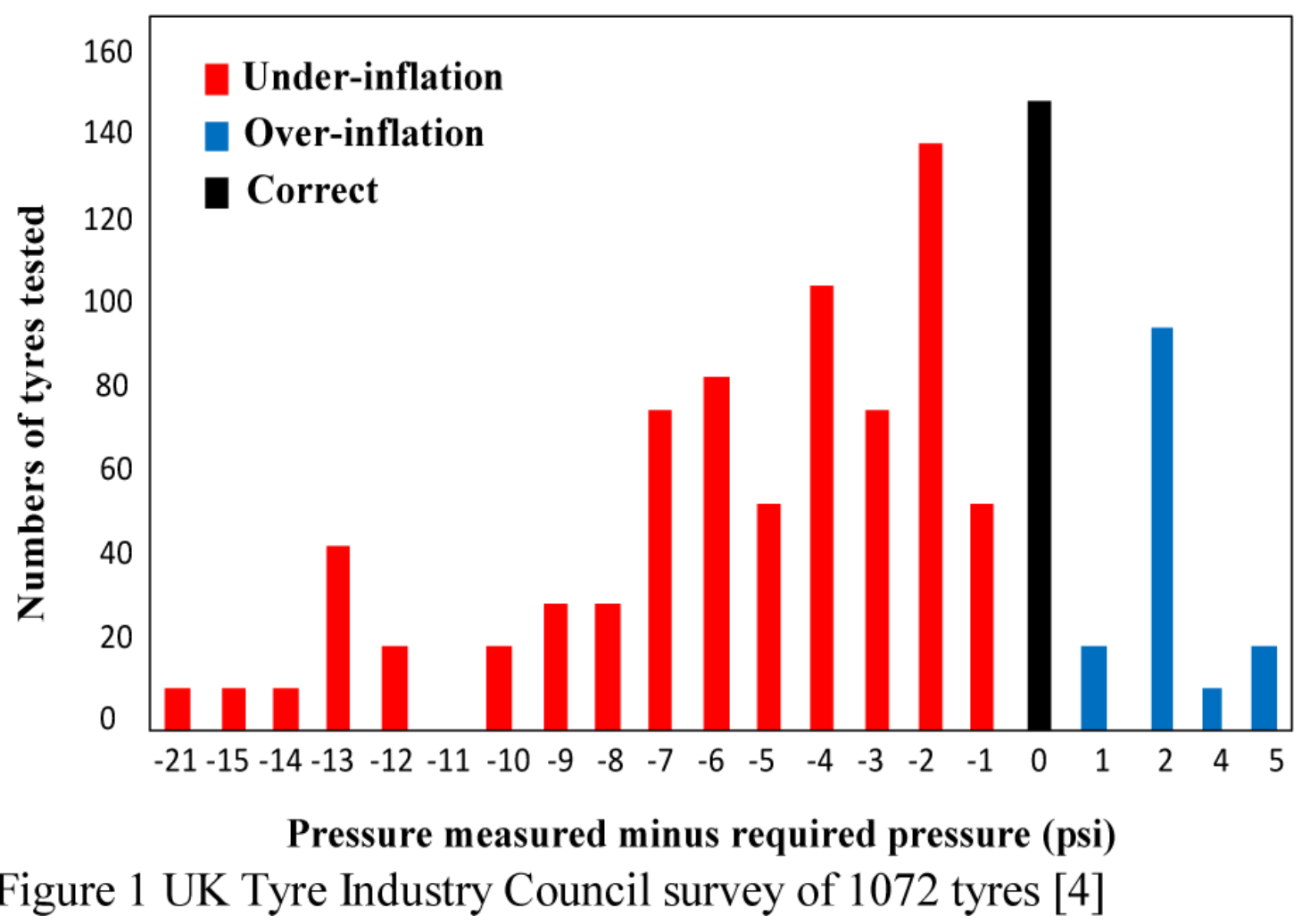

Paine et al [4] presented in a report for Heads of Compulsory Third Party Insurance in Australia and New Zealand that ,in the three years(from 2003 to 2005), tyre defects accounted for up to 50 percent of light vehicle crashes where a vehicle defect was identified as a likely factor in crashed vehicle study. As per the Tyre Industry Council in the UK road side surveys, the tyre pressure effects on the car performance are neglected. They found that from the survey of over 1000 tyres in 2002, only 15 percent were correctly inflated and 72 percent were under inflated as it is shown in Fig. 1.

According to the World Energy Outlook 2006 [5] road transport is responsible for increasing energy uses and Carbon dioxide $\left(\mathrm{CO}_{2}\right)$ emissions globally. Roughly $20 \%$ of a motor vehicle"s fuel is estimated to be used to overcome rolling resistance of tyres. Therefore, tyre is responsible for energy consumption and $\mathrm{CO}_{2}$ emissions.

Furthermore, additional fuel is required when tyres are under-inflated. Data presented at the 2005 International Energy Agency (IEA) Tyre Workshop indicates, the tyres in service are underinflated by 0.2 to 0.4 bar on average for passenger cars and 0.5 bar for trucks [6]. It is generally understood that these numbers correspond to an increase in energy consumption and $\mathrm{CO}_{2}$ emissions of roughly 1 to 2.percent for passenger cars, and 1 percent for trucks.

Rievaj et al [7], has presented the effect of tyre pressure on stopping distance. The influence of the variation in the tyre inflation pressure on the steady state and transient handling dynamics of an urban bus has been discussed by Al-Solihat et al [8], through analysis of a threedimensional (3D) vehicle model. This study concluded that, a lower tyre inflation pressure generally yields higher yaw and roll rates, a higher lateral acceleration of the sprung mass, and greater roll deflections of the unsprung masses, leading to higher load transfer. An indirect tyre pressure monitoring system based on vibration and wheel radius analysis has been presented by Persson and Gustafsson [2]. Borner et al [9], has presented a supervision of the tyre pressure with estimation of the signal spectrum. A signal-based approach has 
been adopted by Weispfenning [10], to estimate the tyre stiffness with spectrum analysis, to check the tyre pressure with parameter estimation.

A good car suspension system should have satisfactory road holding ability, while still providing comfort when riding over bumps and holes in the road [11]. The performance of a passive suspension system is variable subject to the road profiles. In general, terminologies related to suspension performance are ride comfort quality, road handling and stability of the vehicle. Ride comfort is proportional to the absolute acceleration of the vehicle body (sprung mass), and it can be improved by reducing the vehicle body acceleration, while road handling is depend on the relative displacement between vehicle body and the tyres. On the other hand, vehicle stability is linked to the tyre-ground contact [12].

To consider the performances of the suspension in terms of ride quality, handling and stability of the vehicle, some important parameters must be studied. These parameters are the wheel deflection, suspension travel and the vehicle body acceleration. The aim is to achieve small amplitude value for these parameters [13]. Road handling is associated with the relative displacement between suspension and the road input $(\mathrm{Zu}-\mathrm{Zr})$. This is represented as wheel deflection as shown in the Fig. 2. Suspension travel is defined as the relative displacement between the vehicle body and the wheel $(\mathrm{Zs}-\mathrm{Zu})$ as shown in the Fig. 2. This can be used for assessing the space required to accommodate the suspension spring. Ride comfort is related to vehicle body motion sensed by the passenger"s

This requires that the acceleration of the vehicle body (sprung mass) be relatively small. According to ISO: 2631-1-1997[14] the proper road handling must be in the range of $0.0508 \mathrm{~m}$ whilst the standard value for suspension travel must be in the range of minimum of $0.127 \mathrm{~m}$. Finally, the passenger feels highly comfortable if the RMS acceleration is below $0.315 \mathrm{~m} / \mathrm{s} 2$.

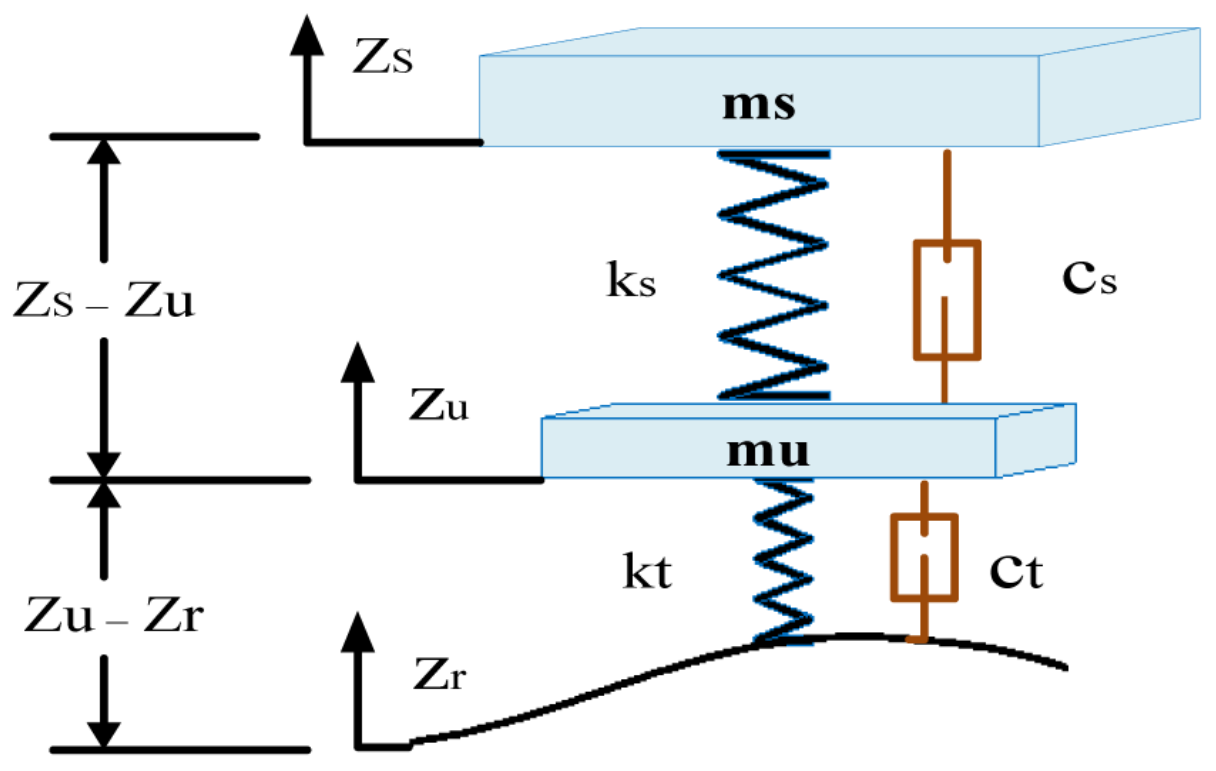

Figure 2 Sketch of quarter car model

A number of researchers have investigated suspension performance using modelling/simulation. A mathematical model for quarter car with 2-DOF and a half car with 4DOF have been investigated by Faheem [15]. Also, a mathematical model of a 3-DOF quarter car with semi-active suspension system has been developed by Rao [16]. The model was used for testing of skyhook and other strategies of semi active suspension system. Modeling of one and two DOF for a quarter car design a semi-active twin-tube shock has been developed by Esslaminasa et al [17]. Darus [18] adopted a state space approach in developing a 
mathematical model for both a quarter car and full car using MATLAB packages. In Metallidis [19], statistical system identification technique was applied for performing parametric identification and fault detection of nonlinear vehicle suspension system. A model-based fault detection applied on a vehicle control system has been presented by Kashi [20], which relies on mathematical descriptions of the system and which yields a robust fault detection and isolation of faults affecting the system. Agharkakli et al [21] presents a mathematical model for passive and active of quarter car suspension system. A research study to improve road handling and rid comfort was presented by Ikenaga et al [22]. Active suspension control system based on a full Vehicle model was presented, and the performance of suspension system was included. The effect of truck speed on the shock and vibration levels was discussed by $\mathrm{Lu}$ et al [23]. They indicated that the effect of truck speed on root mean square acceleration of vibration was strong at a lower speed, but slight at a higher speed.

The objective of this research is to analyses the performances of suspension in terms of ride comfort, road handling and stability. The effect of under-inflated tyres on suspension performance has been investigated. For this a mathematical modelling of the full car has been conducted in this study.

\section{SUSPENSION SYSTEM MODEL AND DYNAMICS}

Development of the vehicle model operates under the assumptions that the vehicle is a rigid body, represented as sprung mass (ms), and the suspension axles are represented as unsprung mass $(\mathrm{mu})$ as shown in Fig. 3. The suspension between the vehicle body and wheels are modelled by linear spring and damper elements and each tyre is modelled by a single linear spring and damper.

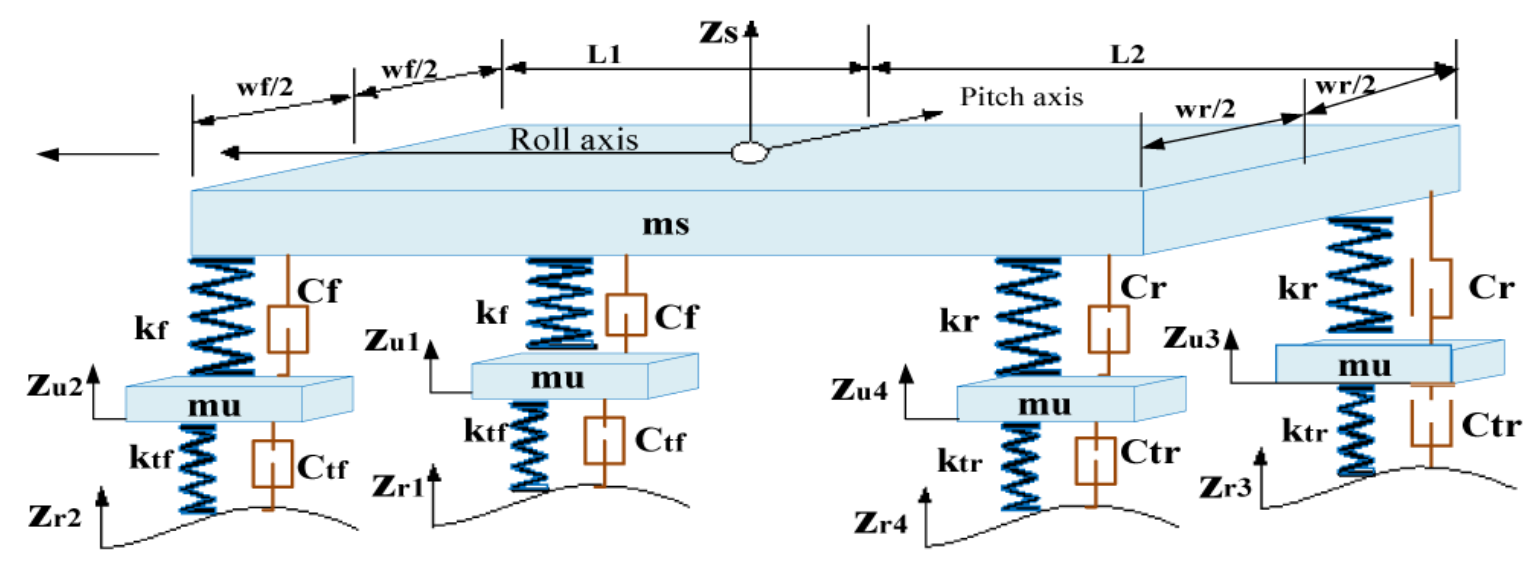

Figure 3 Full vehicle models

The equations of all motions are derived separately, and finally the equations of the body motions are achieved[18].

\section{EXPERIMENTAL SET UP AND TEST PROCEDURES}

To validate the theoretical model, a front wheel drive Vauxhall ZAFIRA (2001) car, equipped with two different sensors was used. The sensors mounted on the car include: (1) a vibration sensor with a sensitivity of $(3.770 \mathrm{pc} / \mathrm{ms}-2)$ mounted on the upper mounting point of the front left shock absorber, and (2) a dynamic tyre pressure sensor (DTPS) with a sensitivity of $(11.43 \mathrm{Pc} / 0.1 \mathrm{Mpa})$ connected to the valve stem of the front left wheel. The pressure sensor 
was situated in the center rim of the front left wheel and the vibration sensor on the inside of the car. They were placed in these positions after being assembled and connected to the wireless sensor nodes (transmitters). The gateway (receiver) was equipped with a laptop inside the car. In order to ensure a sound installation of the sensors, two different adapters were designed and manufactured at the University of Huddersfield. In addition to this, a wireless measurement system was also designed and installed on the car, to offer a complete remote measurement for the vibration and pressure data being extracted. The most fundamental aim of the test was to obtain the acceleration (vibration) response of the suspension system to enable a thorough analysis of the effects that under-inflation of tyres have on the performance of the suspension system.

\section{RESULTS AND DISCUSSION}

The model was validated using experimental data collected when the vehicle was being driven, at a speed of $8 \mathrm{~km} / \mathrm{h}$, over Bump 1 (located within the premises of The University of Huddersfield). The bump profile was $5.80 \mathrm{~m}$ width, $0.50 \mathrm{~m}$ length and $0.050 \mathrm{~m}$ height and this was assumed to be the input for the system. Fig. 4 depicts the acceleration of the vehicle body in the time domain based on the model simulation and experiments. Upon a comparison of the experimental results, it can be noted that the model fairly predicts the suspension performance.

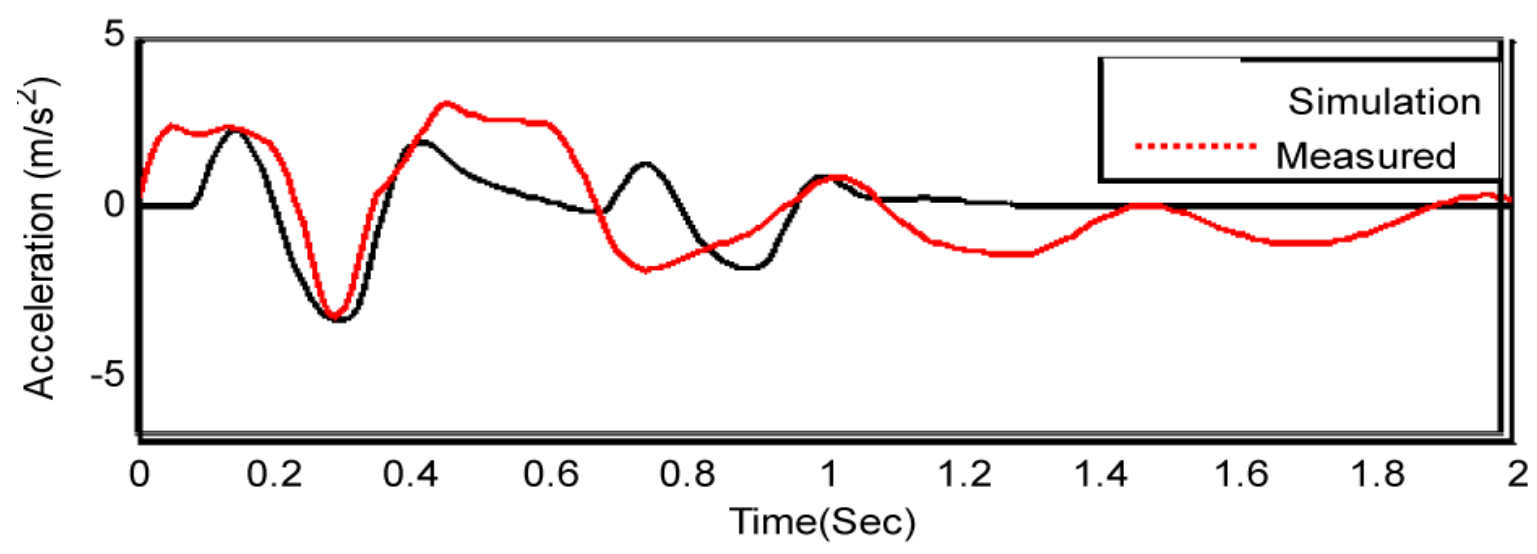

Figure 4 Vibration of suspension simulation and experimental

Fig. 5-a. shows the plots of the road profile in the time domain for both the front and rear wheels of the vehicle. Fig. 5-b shows the effect of varying the tyre pressure on the vehicle body response. From these results, it was observed that a decrease in tyre pressure causes a resultant increase in the amplitude of the relative displacement of the car body. Fig. 6 depicts the displacement of four wheels (unsprung mass) with different tyre pressures in the time domain. The results show an apparent rise in the amplitude of the front wheels when the tyre pressure value was reduced. This indicates that the performance of the suspension may be affected by under-inflated tyres which will be focused on in more detail in the discussions to follow. 
International Letters of Chemistry, Physics and Astronomy Vol. 55

107

(a) Road Profile Exitation

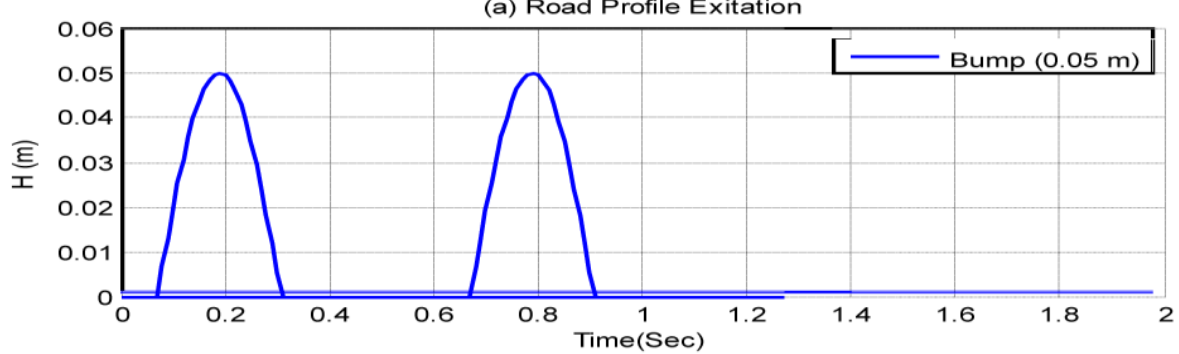

(b) Car Body Displacement

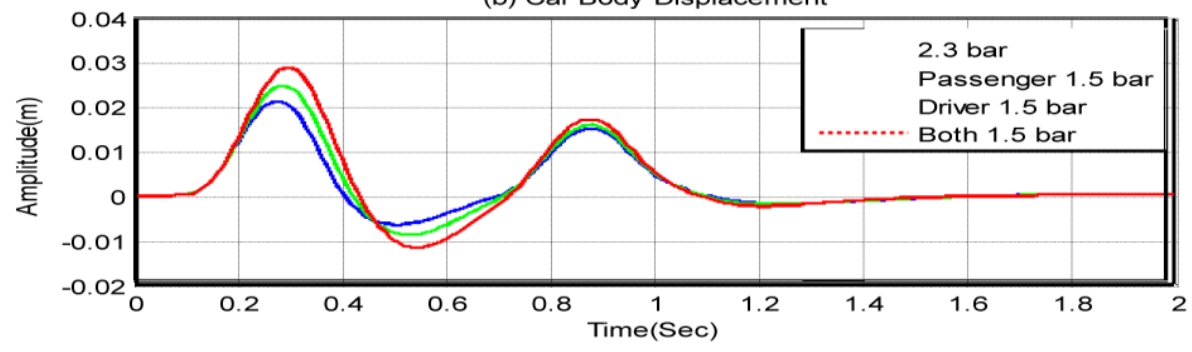

Figure 5 (a) Road profile excitation and (b) displacement of vehicle body for different tyre pressure
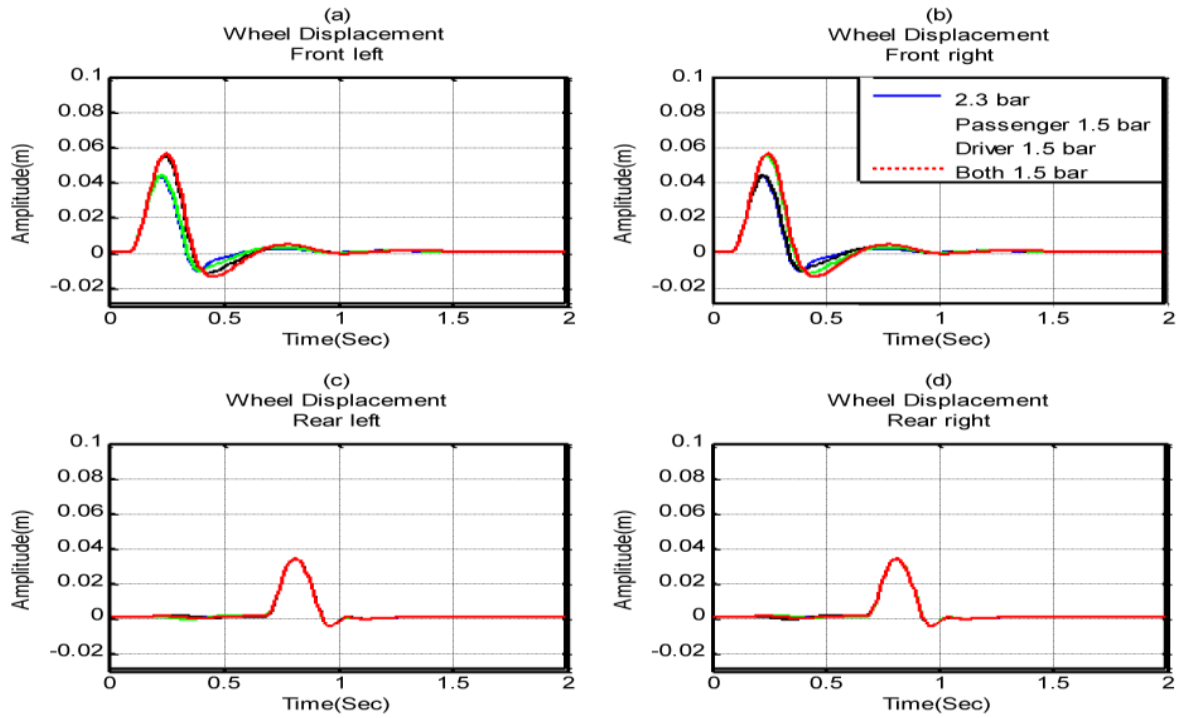

Figure 6 Vehicle wheel "s displacement for different tyre pressure

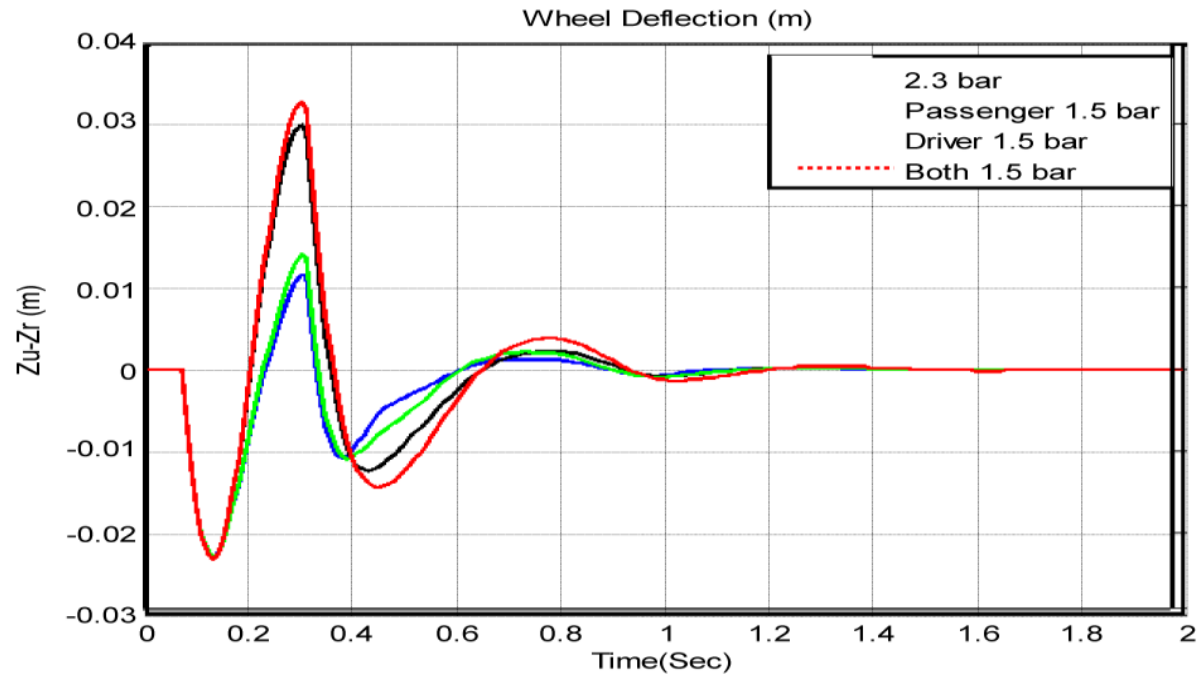

Figure 7 Wheel deflections for different tyre pressure 
The suspension travel can be defined as a relative displacement between the vehicle body and the wheel (zs- zu), Fig. 8 shows the suspension travel values are about $0.0212 \mathrm{~m}, 0.0238 \mathrm{~m}, 0.0257 \mathrm{~m}$ and $0.0289 \mathrm{~m}$ for standard pressure, 1.5 bar passenger, 1.5 bar driver and 1.5 bar both wheels respectively. As it is expected the suspension travel is increasing with decreasing of tyre pressure. But this should be optimized with vehicle handling and stability. Fig. 9shows a typical example of RMS value for acceleration of the vehicle body at different tyre pressure. These results show that the effect of under-inflation of the tyre on the acceleration of the vehicle body. It can be noted that, the RMS value increases with the lowering of the tyre pressure, which indicated that, the ride comfort is affected negatively by under-inflation of the tyre. It can be summarized that, underinflation tyres affect the suspension performance in conflicting criteria, it shows a slight change in terms of road handling, and however, it has a notable affect in terms of ride quality as shown in RMS plots.

To develop a condition monitoring for suspension faults, a transfer function was used to detect the under-inflation of the tyre and also predict possible future suspension faults. In Fig. 11, the amplitude-frequency characteristic curves for different tyre pressure in four different outputs (vehicle body displacement, vehicle body velocity, displacement of front wheel and rear wheel) are presented. From the plots, it can be seen that lowering the tyre pressure, rise thevalue of the suspension displacement at the sprung mass natural frequency, and also reduce the value of the amplitude at wheels natural frequency. From this it can be concluded that under-inflation of the tyre affects clearly the response of the vehicle in the frequency range close to the natural frequency of the vehicle body. However, lowering the tyre pressure provide better vibration isolation in the frequency range of wheels.

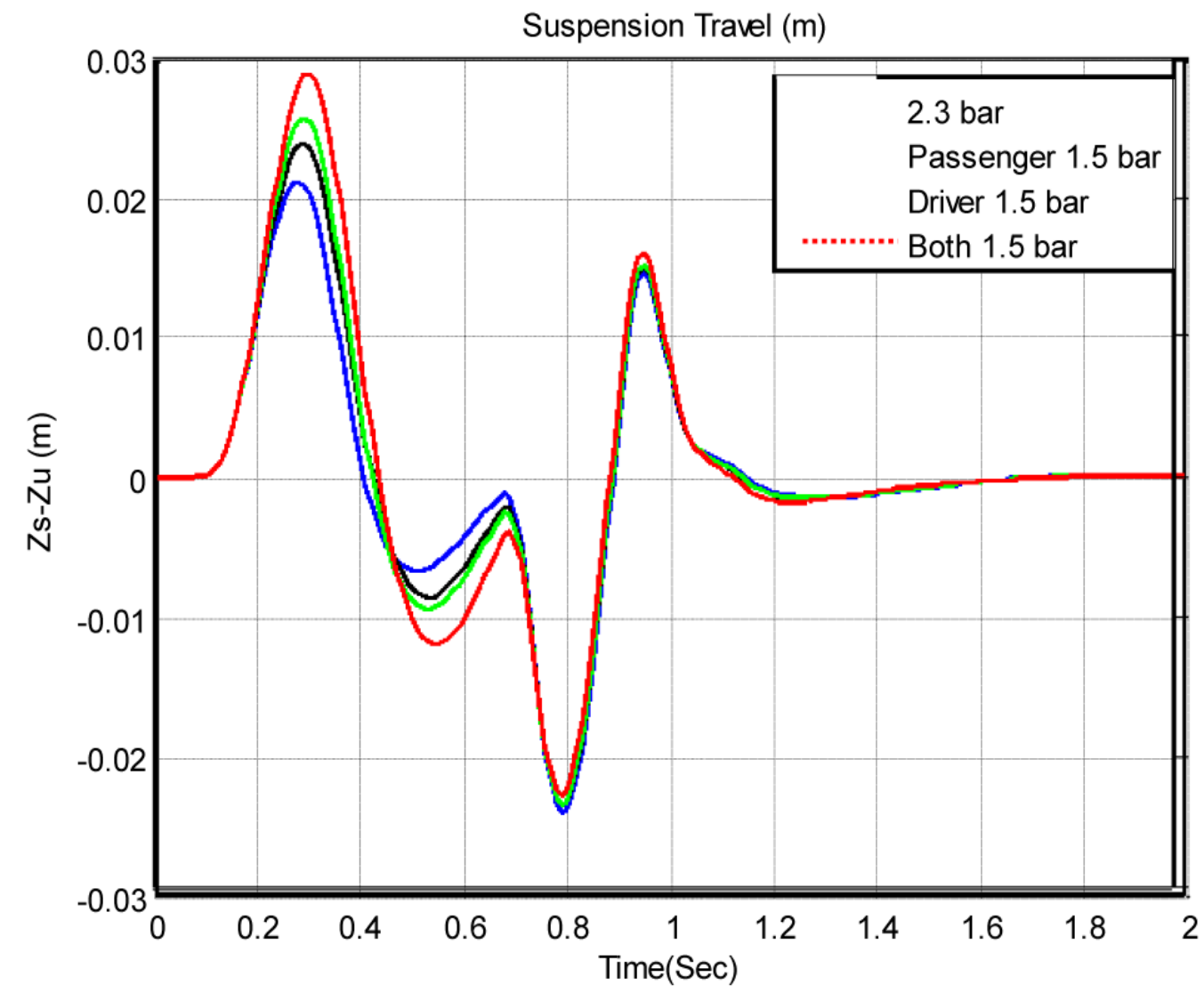

Figure 8 Suspension travel for different tyre pressure 


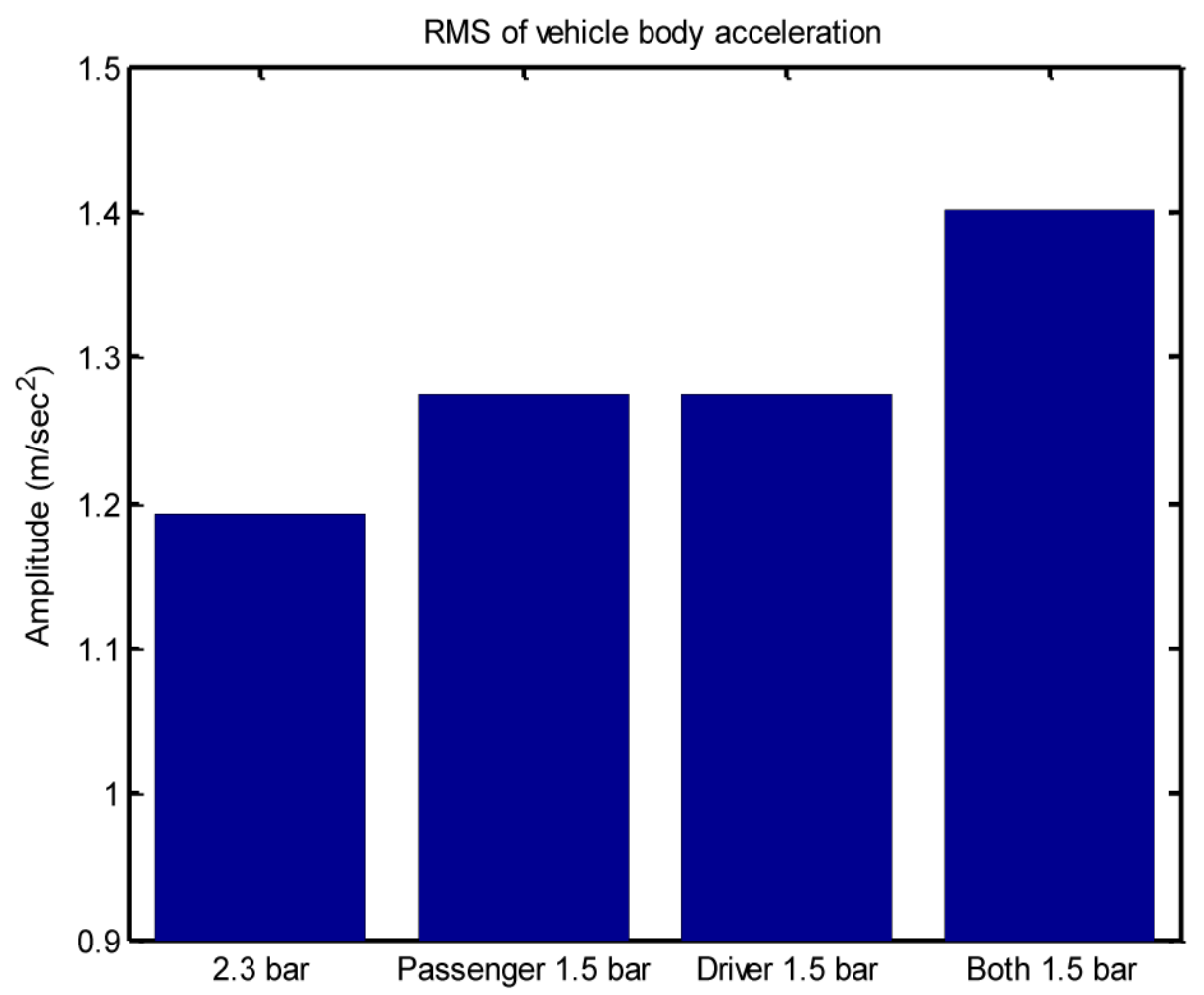

Figure 9 Shows RMS for acceleration of the vehicle body for different tyre pressure

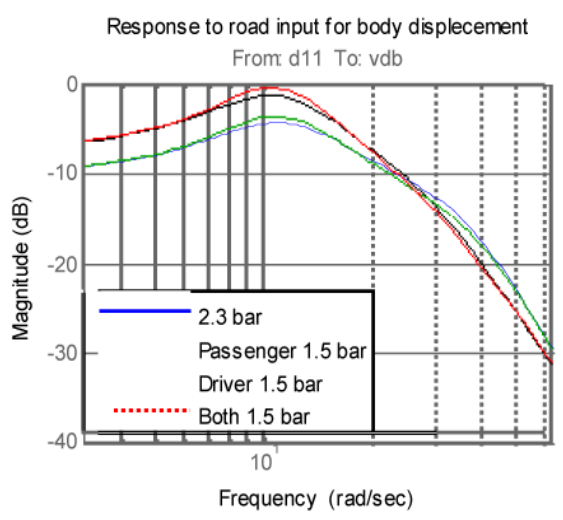

Response to road input for front wheel From d11 To: dfrw

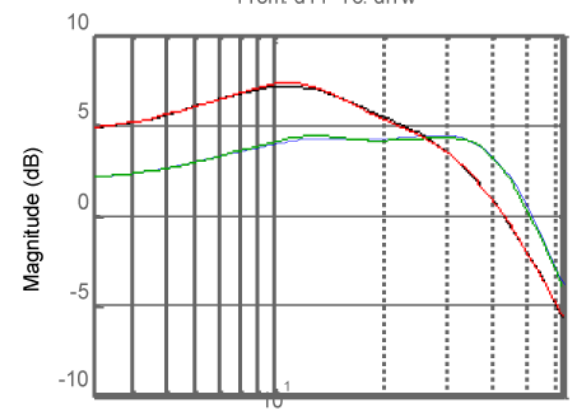

Frequency (rad/sec)
Response to road input for body velocity

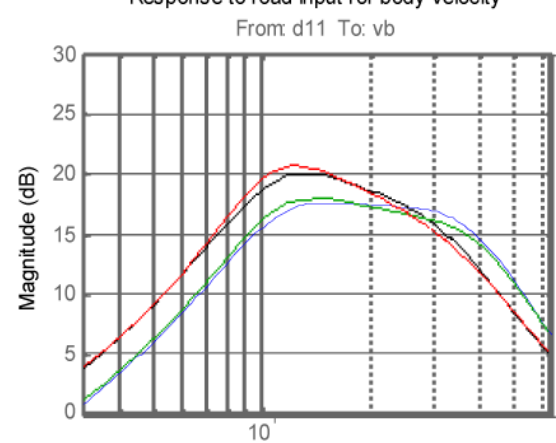

Frequency $(\mathrm{rad} / \mathrm{sec})$

Response to road input for rear wheel From: d11 To: drrw

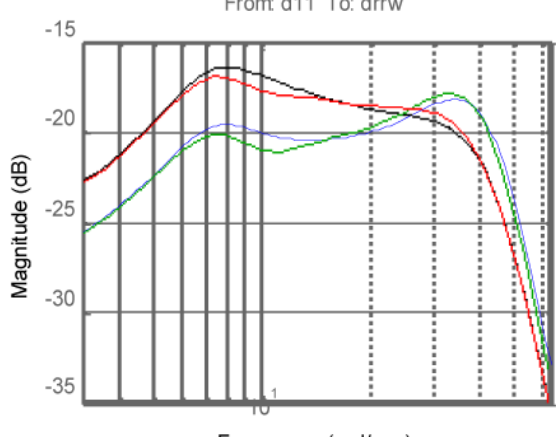

Frequency ( $\mathrm{rad} / \mathrm{sec})$

Figure 10 Transfer function response for vehicle body and vehicle wheels 


\section{CONCLUSION}

A 7-DOF model for a full vehicle has been developed to analyse the time and the frequency response of the vehicle in MATLAB. The effect of under-inflation of the tyre on the performance of the suspension included ride quality; handling and stability of the vehicle were presented. The key findings indicate that, under-inflation tyres affect the suspension performance in conflicting criteria, it shows a slight change in terms of road handling, and however, it has a notable affect in terms of ride quality. It can be also concluded that in the frequency range close to the natural frequency of the vehicle body, the amplitude value of the vehicle response was clearly affected and shows a notable increase.

\section{References}

[1] J. Daws, "I nflation Pressures for Plus - Size Fitments," Int. Tire Exhib. Conf., 2010.

[2] F. Gustafsson, N. Persson, and M. Drevö, "Indirect Tire Pressure Monitoring using Sensor Fusion," presented at the Proceedings of the SAE 2002 World Congress, 2002.

[3] R. Isermann, "Diagnosis Methods for Electronic Controlled Vehicles," Veh. Syst. Dyn., vol. 36, no. 2-3, pp. 77-117, 2001.

[4] Paine, "The Role of Tyre Pressure in Vehicle Safety, Injury and Environment," Heads Compels. Third Party Insur. Aust. N. Z., Feb. 2007.

[5] International Energy Agency, "World Energy Outlook 2006," 2006.

[6] International Energy Agency, "Fuel Efficient Road Vehicle Non-Engine Components," 2007.

[7] V. Rievaj, "Tire Inflation Pressure Influence on a Vehicle Stopping Distances," Int. J. Traffic Transp. Eng., no. 2 (2), pp. 9-13, 2013.

[8] M. K. Al-Solihat, S. Rakheja, and A. K. W. Ahmed, "Influence of tyre pressure on an urban bus transient and steady state handling performance," Proc. Inst. Mech. Eng. Part J. Automob. Eng., vol. 224, no. 7, pp. 893-908, 2010.

[9] M. Börner, H. Straky, T. Weispfenning, and R. Isermann, "Model based fault detection of vehicle suspension and hydraulic brake systems," Mechatronics, vol. 12, no. 8, pp. 999-1010, Oct. 2002.

[10] T. Weispfenning, "Fault Detection and Diagnosis of Components of the Vehicle Vertical Dynamics," Meccanica, vol. 32, no. 5, pp. 459-472, Oct. 1997.

[11] P. S. Els, N. J. Theron, P. E. Uys, and M. J. Thoresson, "The ride comfort vs. handling compromise for off-road vehicles," J. Terramechanics, vol. 44, no. 4, pp. 303-317, Oct. 2007.

[12] A. Rehnberg, "Vehicle dynamic analysis of wheel loaders with suspended axles," 2008.

[13] B. L. Zohir, "Ride Comfort Assessment in Off Road Vehicles using passive and semiactive suspension."

[14] A. Mitra, N. Benerjee, H. Khalane, M. Sonawane, D. JoshI, and G. Bagul, "Simulation and Analysis of Full Car Model for various Road profile on a analytically validated MATLAB/SIMULINK model," IOSR J. Mech. Civ. Eng. IOSR-JMCE, pp. 22-33.

[15] Ahmad Faheem, Fairoz Alam, and V. Thomas, "The suspension dynamic analysis for a quarter car model and half car model," Dec-2006.

[16] R. Rao, T. Ram, k Rao, and P. Rao, "Analysis of passive and semi active controlled suspension systems for ride comfort in an omnibus passing over a speed bump," Oct-2010. 
[17] N. Eslaminasab, M. Biglarbegian, W. W. Melek, and M. F. Golnaraghi, "A neural network based fuzzy control approach to improve ride comfort and road handling of heavy vehicles using semi-active dampers," Int. J. Heavy Veh. Syst., vol. 14, no. 2, pp. 135-157, Jan. 2007.

[18] R. Darus and Y. M. Sam, "Modeling and control active suspension system for a full car model," in 5th International Colloquium on Signal Processing Its Applications, 2009. CSPA 2009, 2009, pp. 13-18.

[19] P. Metallidis, G. Verros, S. Natsiavas, and C. Papadimitriou, "Fault Detection and Optimal Sensor Location in Vehicle Suspensions," J. Vib. Control, vol. 9, no. 3-4, pp. 337359, Mar. 2003.

[20] K. Kashi, D. Nissing, D. Kesselgruber, and D. Soffker, "Diagnosis of active dynamic control systems using virtual sensors and observers," in 2006 IEEE International Conference on Mechatronics, 2006, pp. 113-118.

[21] A. Agharkakli, G. Sabet, and A. Barouz, "Simulation and Analysis of Passive and Active Suspension System Using Quarter Car Model for Different Road Profile," Int. J. Eng. Trends Technol.-, vol. 3, no. 5, 2012.

[22] S. Ikenaga, F. L. Lewis, J. Campos, and L. Davis, "Active suspension control of ground vehicle based on a full-vehicle model," in American Control Conference, 2000. Proceedings of the 2000, 2000, vol. 6, pp. 4019-4024 vol.6.

[23] F. Lu, Y. Ishikawa, H. Kitazawa, and T. Satake, "Effect of vehicle speed on shock and vibration levels in truck transport," Packag. Technol. Sci., vol. 23, no. 2, pp. 101- 109, 2010.

[24] J. Y. Wong, Theory of Ground Vehicles. John Wiley \& Sons, 2001. 